\section{Commentary: Postoperative atrial fibrillation, predictor of late risk?}

\author{
Vincent R. Conti, MD
}

The report by Almassi and colleagues ${ }^{1}$ describing the late outcomes of new-onset postoperative atrial fibrillation (POAF) in the randomized Veteran's Affairs on/off bypass (ROOBY) trial has added significant reassurance that this complication does not predict compromised 5-year outcomes or survival. The authors clearly identify the limitations of their study, especially that nearly all their trial subjects were male and that there were some limitations in late follow-up, especially the late incidence of stroke. Nevertheless, this trial and their analysis does support the lack of any difference in POAF due to the choice of onpump versus off-pump procedure and the absence of late risk of cardiac or all-cause mortality at 5 years. The authors are careful to note that comprehensive risk adjustment was used to focus on POAF as an independent risk factor and that although 1-year risks were higher, risk-adjusted 5year risks were not. They carefully document and discuss multiple other studies that have assessed the longer-term risks associated with POAF and stress that their study used superior risk adjustment to focus on POAF as the true predictor of these outcomes.

Recent similar studies not reported by the authors have identified POAF as an independent risk factor. The EXCEL trial looked at the effect of new-onset POAF after PCI or CABG for left main disease and documented increased a 3 -year risk of death or stroke in the patients undergoing CABG. $^{2}$

Another carefully risk-adjusted study concluded that POAF lasting less than 2 days was associated with no change in survival, whereas POAF lasting 2 days or longer was associated with decreased survival.

This data should motivate implementation of interventions that may decrease the risk of POAF and careful

\footnotetext{
From the Division of Cardiovascular and Thoracic Surgery, Department of Surgery, University of Texas Medical Branch, Galveston, Tex.

Disclosures: Author has nothing to disclose with regard to commercial support.

Received for publication Oct 30, 2019; revisions received Oct 30, 2019; accepted for publication Oct 30, 2019; available ahead of print Nov 27, 2019.

Address for reprints: Vincent R. Conti, MD, Department of Surgery, University of Texas Medical Branch, 301 University Blvd, Galveston, TX 77555 (E-mail: vconti@utmb.edu).

J Thorac Cardiovasc Surg 2021;161:1811-2

$0022-5223 / \$ 36.00$

Copyright (c) 2019 by The American Association for Thoracic Surgery

https://doi.org/10.1016/j.jtcvs.2019.10.200
}

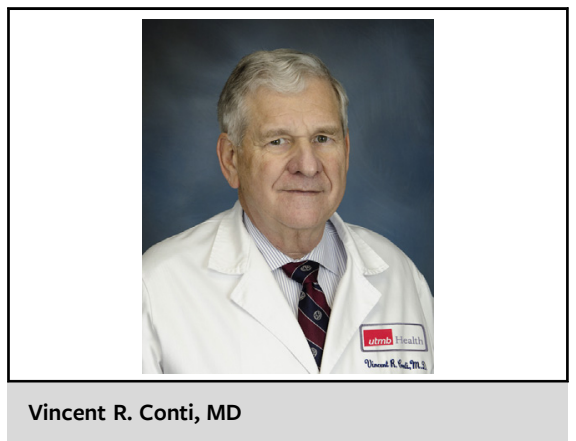

CENTRAL MESSAGE

This study highlights the shortand long-term risks and costs associated with new-onset atrial fibrillation and provides motivations to prevent episodes in the future.

follow-up and management of patients who have experienced POAF. A decreased incidence of POAF has been achieved by active clearance of chest drainage catheters, thereby avoiding posterior accumulation of pericardial blood, ${ }^{4,5}$ and by overdrive atrial pacing, particularly biatrial pacing for the first 3 postoperative days. ${ }^{6,7}$ Multiple pharmacologic interventions also have proven effective, including maintaining beta blocker therapy, ${ }^{8}$ administration of statins, particularly atorvastatin, ${ }^{9}$ and adding antiarrhythmics such as amiodarone, although many surgeons avoid this as a preventive measure because of its potential complications. ${ }^{10}$ Although it is certainly desirable to prevent POAF, this study confirms that risk factors predisposing to POAF will still be operative and a determinant of late survival.

\section{References}

1. Almassi GH, Hawkins RB, Bishawi M, Shroyer AL, Hattler B, Quin JA, et al. New-onset postoperative atrial fibrillation impact on 5-year clinical outcomes and costs. J Thorac Cardiovasc Surg. 2021;161:1803-10.e3.

2. Kosmidou I, Chen S, Kappetein AP, Serruys PW, Gersh BJ, Puskas JD, et al. New-onset atrial fibrillation after PCI or CABG for left main disease: the EXCEL trial. J Am Coll Cardiol. 2018;71:739-48.

3. Sigurdsson MI, Longford NT, Heydarpour M, Saddic L, Chang TW, Fox AA, et al. Duration of postoperative atrial fibrillation after cardiac surgery is associated with worsened long-term survival. Ann Thorac Surg. 2016;102:2018-26.

4. St-Onge S, Ben Ali W, Bouhout I, Bouchard D, Lamarche Y, Perrault LP, et al. Examining the impact of active clearance of chest drainage catheters on postoperative atrial fibrillation. J Thorac Cardiovasc Surg. 2017;154:501-8.

5. St-Onge S, Perrault LP, Demers P, Boyle EM, Gillinov AM, Cox J, et al. Pericardial blood as a trigger for postoperative atrial fibrillation after cardiac surgery. Ann Thorac Surg. 2018;105:321-8. 
6. Blommaert D, Gonzalez M, Mucumbitsi J, Gurné O, Evrard P, Buche M, et al. Effective prevention of atrial fibrillation by continuous atrial overdrive pacing after coronary artery bypass surgery. J Am Coll Cardiol. 2000;35:1411-5.

7. Greenberg MD, Katz NM, Iuliano S, Tempesta BJ, Solomon AJ. Atrial pacing for the prevention of atrial fibrillation after cardiovascular surgery. J Am Coll Cardiol. 2000;35:1416-22.

8. Budeus M, Feindt P, Gams E, Wieneke H, Sack S, Erbel R, et al. Beta-blocker prophylaxis for atrial fibrillation after coronary artery bypass grafting in patients with sympathovagal imbalance. Ann Thorac Surg. 2007;84:61-6.

9. Elgendy IY, Mahmoud A, Huo T, Beaver TM, Bavry AA. Meta-analysis of 12 trials evaluating the effects of statins on decreasing atrial fibrillation after coronary artery bypass grafting. Am J Cardiol. 2015;115:1523-8.

10. Mehaffey JH, Hawkins RB, Byler M, Smith J, Kern JA, Kron I, et al. Amiodarone protocol provides cost-effective reduction in postoperative atrial fibrillation. Ann Thorac Surg. 2018;105:1697-702.
See Article page 1803

\section{Commentary: Postoperative atrial fibrillation: "No magic bullet"}

\author{
Scott M. Goldman, MD
}

In this issue of the Journal, Almassi and colleagues ${ }^{1}$ reference a 2012 article $^{2}$ analyzing a subgroup of the Veterans Affairs Randomized On/Off Bypass follow-up study (ROOBY-FS). ${ }^{3}$ In 2012, Almassi's group compared patients who developed atrial fibrillation during the hospitalization for the index procedure-postoperative atrial fibrillation (POAF) - and those who did not. They had previously reported risk-adjusted poorer outcomes and increase cost at a 1-year follow-up in patients who developed POAF. ${ }^{4}$ When analyzed at 5 years, these differences were not evident. There were no differences in the incidence of POAF between on-pump and off-pump coronary artery bypass. Beyond the first year, there were no differences in cost between those who developed POAF and those who did not. Almost all the increased cost at 1 year was attributed to those costs associated with the occurrence of POAF during the original hospitalization. As noted in the unadjusted data, the POAF group was older and had more complex comorbidities. This increased risk has also been demonstrated in other studies. $^{5}$

By risk-adjusting the data, this study sheds more light on the patient population that is at increased risk for the development of POAF. They are older and have more

From the Lankenau Heart Institute, Lankenau Medical Center, Wynnewood, Pa.

Disclosures: Author has nothing to disclose with regard to commercial support.

Received for publication Nov 13, 2019; revisions received Nov 13, 2019; accepted for publication Nov 13, 2019; available ahead of print Dec 7, 2019.

Address for reprints: Scott M. Goldman, MD, Lankenau Heart Institute, Lankenau Medical Center, 100 Lancaster Ave, Wynnewood, PA 19096 (E-mail: goldmans@mlhs.org).

J Thorac Cardiovasc Surg 2021;161:1812-3

$0022-5223 / \$ 36.00$

Copyright $($ c 2019 by The American Association for Thoracic Surgery

https://doi.org/10.1016/j.jtcvs.2019.11.067
Check for updates

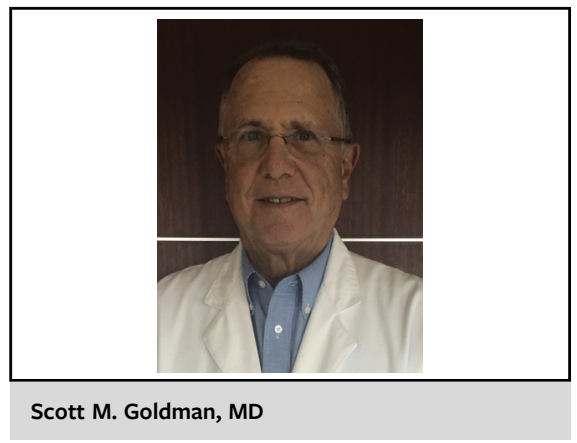

CENTRAL MESSAGE

Only by considering the risk of postoperative atrial fibrillation in each patient and pursuing a ho-

listic strategy are we likely to make a dent in the $30 \%$ inci-

dence rate.

comorbidities, and it is evident from this and other studies ${ }^{5,6}$ that the burden surrounding POAF occurs during index hospitalization and the early postdischarge period.

Over the last 3 decades, the incidence of POAF has remained near $30 \%$ despite overall improvements in outcomes and postoperative care. ${ }^{6}$ There have been many attempts to identify the single intervention that will have a major impact on this. These include both pharmacologic and operative interventions.

Operative modifications that have been tried include posterior pericardiotomy, left atrial appendage exclusion, and anterior fat pad preservation. ${ }^{7-9}$ These have not proven effective. Left atrial appendage exclusion may increase the rate of POAF. ${ }^{6,10}$ Atrial and biatrial pacing have been studied, with mixed results. ${ }^{11}$

The administration of beta blockers is the only class 1a indicated pharmacologic intervention for the prevention 